\title{
Experimental and numerical study on GFRP-glass adhesively bonded joints
}

\author{
L. Valarinho, J.R. Correia, F.A. Branco \\ Instituto Superior Técnico/ICIST, Universidade de Lisboa
}

J. Sena-Cruz

School of Engineering/ISISE, University of Minho

\begin{abstract}
This paper presents experimental and numerical investigations on adhesively bonded double lap joints composed of glass and GFRP pultruded profiles. The experimental programme comprised the study of the effects of using three different adhesives (with varying stiffness) on the bond behaviour of the joints in terms of stiffness, strength, ultimate displacement and axial strain development along the GFRP-adhesive interface. In the numerical study, 2D finite element models of the joints were developed in order to simulate the bond behaviour observed in the experiments. Interface elements with either linear or non-linear bond-slip constitutive relations were used to simulate the adhesive layers and their shear properties. The numerical models were validated by comparing experimental and numerical load vs. relative displacement curves and their accuracy was further verified through comparison of the load vs. axial strain distributions along the interfaces.
\end{abstract}

\section{INTRODUCTION}

In the last few years the development of glass industry and technology has promoted an increasing use of glass, especially for load bearing purposes. At the same time, the major limitations attributed to glass (its relatively low tensile strength and brittle behaviour) are being overcome by several different approaches, such as (i) the introduction of new materials that improve the structural behaviour of glass (e.g., the use of stiffer and high performance interlayers in laminated glass sheets), (ii) the use of new methods for connecting glass to other materials, thus providing a better distribution of stresses (e.g., the development of adhesive connections), and (iii) new methods to improve the post-fracture behaviour, such as the development of composite glass beams where glass is carefully assembled to different materials (e.g., wood, stainless steel, concrete or GFRP).

Within the latter approach, in the last few years the authors have been developing a composite system made of annealed glass panes and glass fibre reinforced polymer (GFRP) pultruded laminates (Correia et al. 2011, Valarinho et al. 2013). The underlying principle of this composite system, similar to that of reinforced concrete, relies on the stress transfer between the glass pane and the strengthening material when the tensile strength of glass is attained, thus ensuring post-fracture residual strength and deformation capacity. The research has also been supported by the development of numerical models that allow the simulation of the post-fracture behaviour of this kind of solution. For now the numerical models were able to reproduce with high accuracy the post-fracture behaviour of beams bonded with adhesives that provide a high level of interaction at bonded interfaces, allowing the assumption of complete interaction between the two materials (Valarinho et al. 2012). This is related with the fact that there is lack of information on the literature about the mechanical characteristics of adhesively bonded connections between glass and GFRP, namely comprising different types of adhesives. 
This paper describes the results of an experimental and numerical study on adhesively bonded double lap joints between glass and GFRP pultruded profiles. The first part of the paper describes the experimental program, which consisted of tensile tests on double lap joints between GFRP, glass and three different adhesives. The adhesives were chosen in order to cover a wide range of material stiffnesses and behaviours and this selection was not restricted to the use of adhesives that ensure high interaction level between glass and GFRP. The second part of this paper describes the numerical simulation of the double lap joints tested. Two-dimensional finite element models were developed using FEMIX software (Sena-Cruz et al. 2007), in order to reproduce the bond behaviour granted by the three different adhesives taking into account their shear properties. The adhesive layers were simulated using interface elements that required the definition of appropriate bond-slip constitutive laws, either linear or non-linear, depending on the type of adhesive (the non-linear law also allows considering a post-peak branch that simulates debonding process). The numerical models were validated by the comparison of the numerical load $v s$. relative displacement curves with those measured in the experimental tests and their accuracy was further verified through the comparison between calculated and measured load $v s$. axial strains along the interfaces.

The results of the present study, namely the adequate characterization and simulation of the properties of the interface elements that describe the adhesive layers used to bond the GFRP reinforcements to the glass beams will allow improving the previous numerical models of glassGFRP composite beams. As already mentioned, in those preliminary models, the simulation was restricted to beams that were bonded with adhesives that granted full interaction between both materials. Results of the present study will be used to simulate the behaviour of beams bonded with different adhesives that provide partial shear interaction at the bonded interfaces, thereby allowing the simulation of their pre- and post-cracking behaviours.

\section{EXPERIMENTAL INVESTIGATIONS}

\subsection{Specimen geometry}

In order to characterize the behaviour of adhesively bonded joints between GFRP and glass, double-lap joint specimens were prepared and tested in tension. The joints comprised two inner GFRP laminates $\left(10 \times 50 \mathrm{~mm}^{2}\right)$ and two outer glass panes $\left(12 \times 50 \mathrm{~mm}^{2}\right)$ bonded with three different types of adhesives: (i) an elastic gap-filling polyurethane adhesive (Sikaflex 265); (ii) a structural polyurethane adhesive (Sikaforce 7710-L100); and (iii) a structural epoxy adhesive (Sikadur 31-cf) (from now on referred to as Sikaflex, Sikaforce and Sikadur). Both adherends presented a length of $350 \mathrm{~mm}$ and the overlap length was set to $100 \mathrm{~mm}$. Two different thicknesses were used for the interfaces layers: $2 \mathrm{~mm}$ for the Sikaflex and for the Sikadur adhesives and $1 \mathrm{~mm}$ thick for the Sikaforce adhesive. The thickness of the adhesive layers was ensured by means of small PVC spacers, occupying no more than $1 \%$ of the bonding area. The geometry of the specimens is shown in Figure 1.
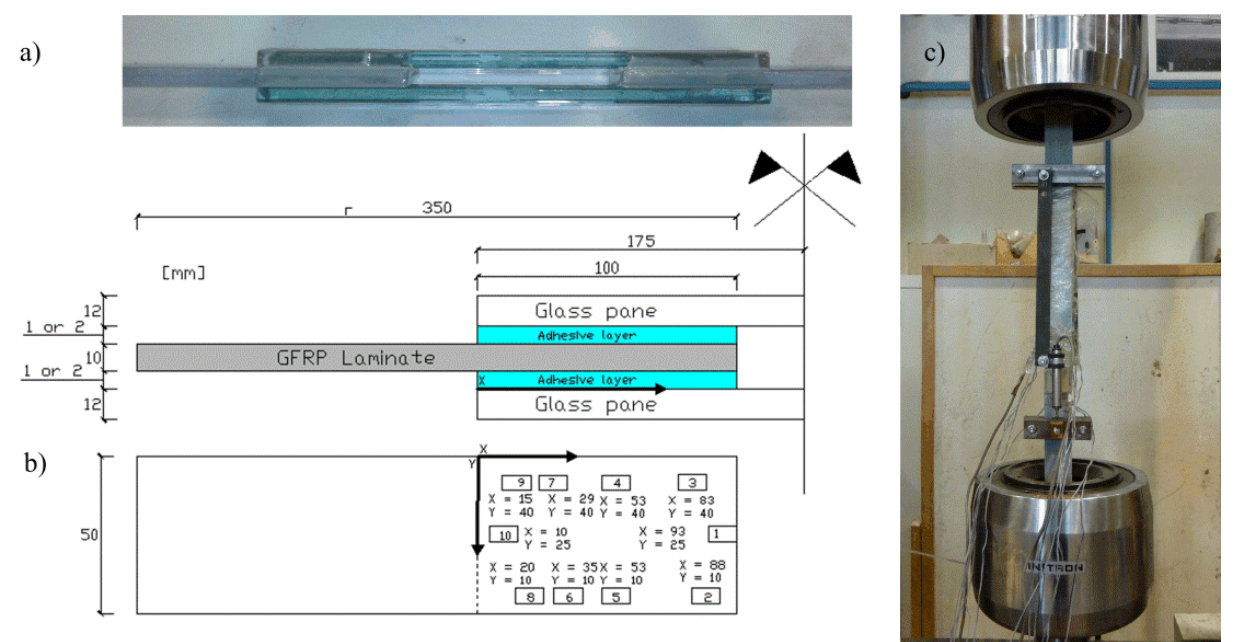

Figure 1. Geometry of the double lap joints (a), position of the strain gauges (b) and (c) tensile test setup 
In order to ensure the quality of the adhesion process, the GFRP surfaces were mechanically abraded with a fine sander until the first fibre mats became visible and then cleaned and degreased using acetone. The glass surfaces were only cleaned and degreased with acetone prior to bonding. The assembly of the adherends was made in two steps, separated by a minimum period of $48 \mathrm{~h}$ to guarantee a sufficient degree of curing of the adhesives before handling the specimens. All specimens were then cured at room temperature $\left(20^{\circ} \mathrm{C}\right)$ for two months.

\subsection{Adherent and adhesive properties}

The elasticity modulus $(E)$ and the ultimate tensile strength $\left(\sigma_{u}\right)$ of the materials used in the experiments (glass, GFRP profiles and three different adhesives) are summarized in Table 1.

Table 1. Mechanical properties in tension of the materials used in the experiments (average \pm standard deviation).

\begin{tabular}{lll}
\hline Material & $\mathrm{E}[\mathrm{MPa}]$ & $\sigma_{\mathrm{u}}[\mathrm{MPa}]$ \\
\hline Glass & 70000 & $58.9 \pm 12.6$ \\
GFRP & $32800 \pm 900$ & $475.5 \pm 25.5$ \\
Polyurethane Sikaflex 265 & $1.49 \pm 0.22$ & 3.4 \\
Polyurethane Sikaforce 7710-L100 & $283 \pm 35$ & $9.2 \pm 0.7$ \\
Epoxy Sikadur-31 cf & $4661 \pm 330$ & $13.1 \pm 3.1$ \\
\hline
\end{tabular}

The outer adherends of the double-lap joints were made of $12 \mathrm{~mm}$ thick annealed glass panes with polished edges. The ultimate tensile stress of glass listed in Table 1 was determined from four point flexural tests performed according to EN 1288-1 (CEN, 2000) and described in (Valarinho et al. 2013). In what concerns the tensile strength of glass, although the scatter was relatively low, it has been reported in the literature that it may present high variability, with strength values ranging from $20 \mathrm{MPa}$ to $70 \mathrm{MPa}$. This is intimately related with the nature of the fracture mechanics of glass, object of several earlier studies (Vandebroek et al. 2012, Veer \& Rodichev 2012).

The GFRP profiles used as inner adherends were made of an isophthalic polyester matrix reinforced with alternating layers of E-glass rovings and mats. The tensile characterization tests were made according to ISO 527-1,4 (ISO 1993) and are described in detail in (Valarinho et al. 2013).

As already mentioned, three different adhesives were used to bond glass and GFRP adherends: Sikaflex, Sikaforce and Sikadur. These three adhesives were chosen in order to cover a wide range of material stiffnesses (Table 1), thus allowing to study the influence of this parameter on the bond behaviour between glass and GFRP. The mechanical properties of the adhesives were determined according to the ISO 527-1,2 (ISO 1993) standard, i.e. by means of tensile tests on dumbbell specimens.

Figure 2 presents the load $v s$. cross-head displacement curves of representative specimens of the three different adhesives. It can be seen that the Sikaflex adhesive presented a typical elastomeric behaviour, exhibiting several different stages in its load-displacement curve (Fig. 2a), presenting a very high deformability and very low ultimate stress. The Sikaforce and the Sikadur adhesives exhibited non-linear behaviour, with the latter adhesive presenting higher elasticity modulus and ultimate stress when compared with the other two adhesives - Figs. $2 \mathrm{~b}$ and $2 \mathrm{c}$.
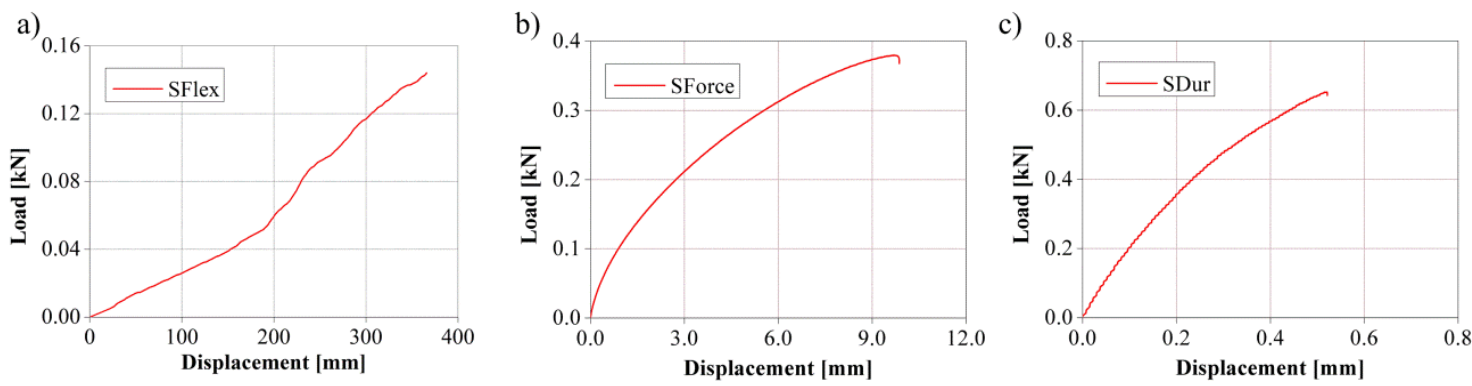

Figure 2. Load vs. displacement curves of a representative specimen from (a) Sikaflex (b) Sikaforce and (c) Sikadur (Valarinho et al. 2013). 


\subsection{Tests on double lap joints - instrumentation, measurements and test setup}

For each type of adhesive, two specimens were tested, one of them specimens being instrumented with strain gauges. The axial strain development along the bonded areas was measured using a set of 10 strain gauges, bonded in the inner surface of one of the GFRP adherends. The distribution of the strain gauges along the bonded length is depicted in Figure 1b. The higher concentrations of gauges in the vicinity of the joint edges aimed at registering the expected peak strains in those regions, especially for the stiffer adhesives. An additional strain gauge was used to measure the strain in the GFRP adherend outside the bonded area.

Specimens were loaded in tension using an Instron universal testing machine under displacement control at a speed of $0.017 \mathrm{~mm} / \mathrm{s}$ (displacement between grips). The applied load and the relative displacement between the extremities of both overlap zones were measured during the tests. For this purpose, two APEK displacement transducers with a stroke of $10 \mathrm{~mm}$ and precision of $0.01 \mathrm{~mm}$ were placed in both sides of the test specimens - Fig. 1c. Prior to testing, specimens were wrapped with cellophane film in order to prevent the dispersion of glass fragments after material breakage. The tests were conducted at room temperature.

\section{EXPERIMENTAL RESULTS}

\subsection{Load vs. displacement response}

Figure 3 presents the load $v s$. relative displacement curves of specimens made of the three different adhesives tested (Sikaflex, Sikaforce and Sikadur). Table 2 presents a comparison of the average results obtained for the different specimens in terms of stiffness $(\mathrm{K})$, maximum load $\left(\mathrm{F}_{\max }\right)$, corresponding relative displacement $\left(\mathrm{d}_{\max }\right)$ and failure modes.
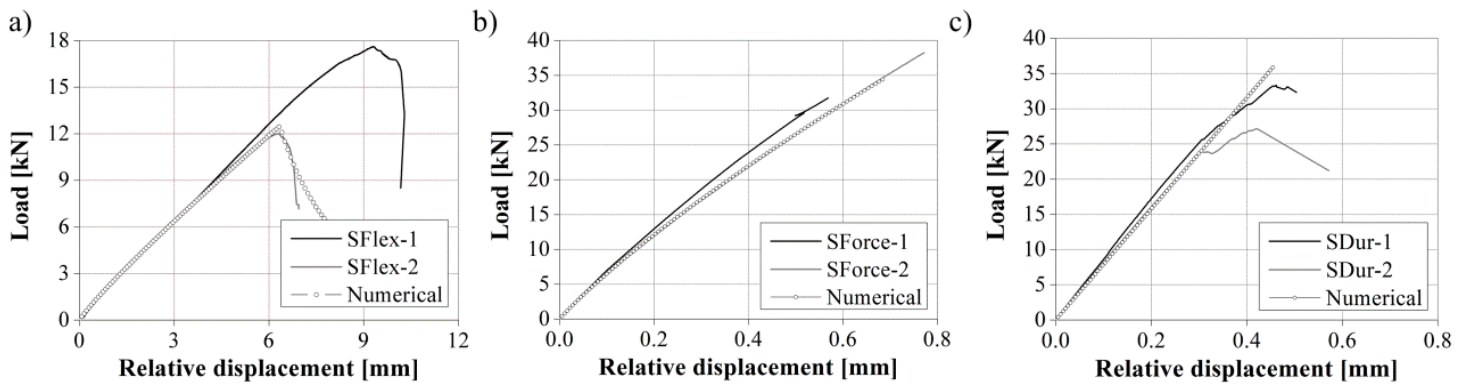

Figure 3. Load $v s$. relative displacement experimental and numerical curves of double lap joint specimens bonded with (a) Sikaflex, (b) Sikaforce and (c) Sikadur adhesives.

Table 2: Summary of average results from tests on double lap joints: stiffness $(\mathrm{K})$, maximum load $\left(\mathrm{F}_{\max }\right)$, deflection at maximum load $\left(\mathrm{d}_{\max }\right)$ and failure modes.

\begin{tabular}{lllll}
\hline Adhesive Type & $\begin{array}{l}\mathrm{K}_{\text {double-lap }} \\
{[\mathrm{kN} / \mathrm{mm}]}\end{array}$ & $\begin{array}{l}\mathrm{F}_{\max } \\
{[\mathrm{kN}]}\end{array}$ & $\begin{array}{l}\mathrm{d}_{\max } \\
{[\mathrm{mm}]}\end{array}$ & Failure mode \\
\hline Polyurethane Sikaflex 265 & 2.18 & 14.8 & 7.82 & Adhesive \\
Polyurethane Sikaforce 7710-L100 & 67.5 & 36.8 & 0.68 & Stock -break (glass) \\
Epoxy Sikadur-31 cf & 85.0 & 30.3 & 0.46 & Stock -break (glass) \\
\hline
\end{tabular}

The load vs. deflection curves of Sikaflex specimens first presented a slightly non-linear behaviour (Fig. 2a) and then exhibited a linear response. However, in the brink of collapse, a high loss of stiffness was noticed due to the debonding in one of the glass-adhesive interfaces, which consequently caused the ultimate failure of the joint. The differences between ultimate loads of both specimens were related with the initial adhesion conditions granted by this adhesive. Its high viscosity not always allowed a completely uniform bond between all interfaces.

Sikaforce double lap joint specimens exhibited a slightly non-linear behaviour (Fig. 2b), with a constant and marginal loss of stiffness. Since failure was caused by glass breakage ( $c f$. section 3.3), unlike the previous adhesive, the differences exhibited in terms of ultimate load should be related with the variability of the ultimate stress of glass.

Sikadur specimens exhibited a practically linear behaviour until failure (Fig. 2c), without significant changes in stiffness during loading. The behaviour was very similar between both spec- 
imens and, as for the Sikaforce adhesive, a progressive damage at the joint areas was registered, although without loss of shear stress transfer capacity.

The stiffness exhibited by the three different adhesives were in line with the results of the tensile characterization tests, in which the Sikaflex adhesive presented a much lower stiffness than the two other adhesives (about 30 times lower than Sikaforce and about 40 times lower than Sikadur). The relative difference between the shear stiffness of the Sikaforce and the Sikaflex adhesives was lower than that between the axial stiffness of the corresponding joints (the difference in terms of $\mathrm{E}_{\text {adhesive }}$ was about 200 times and in terms of $\mathrm{K}_{\text {double-lap }}$ it was only about 1.3). Those small differences are mostly related with the fact that the adhesive layers of those specimens are also different (1 $\mathrm{mm}$ in Sikaforce and $2 \mathrm{~mm}$ in Sikadur): thinner adhesive layers provide higher shear stiffness.

\subsection{Axial strains}

The axial strains development along the interfaces were measured by means of strains gauges bonded along the GFRP-adhesive interface of one specimen of the three adhesives tested. Figure 4 shows the distributions of axial strains along the length of such interface at a load of $5.0 \mathrm{kN}$ for the Sikaflex adhesive and $20.0 \mathrm{kN}$ for the Sikaforce and Sikadur adhesives (numerical results, discussed in section 4 , are also plotted).

The experimental results obtained in terms of axial strains were in line with the load $v s$. relative displacement curves, as well as with the material characterization tests. In other words, the differences in axial stiffness between the three adhesives were also noticed on the distribution of axial strains: for the Sikadur adhesive, the stiffest one, a higher shear stress transfer develops in the initial length of the bonded interface, with a higher concentration of stresses developing in that region. For decreasing adhesive stiffness, in spite of the typical scatter associated with this type of strain measurements, it was possible to observe a linearization tendency of the shear stress transfer along the interface, with the Sikaflex adhesive, the most flexible one, presenting a roughly linear distribution.

a)

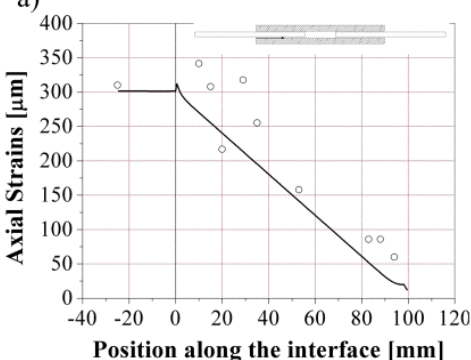

b)

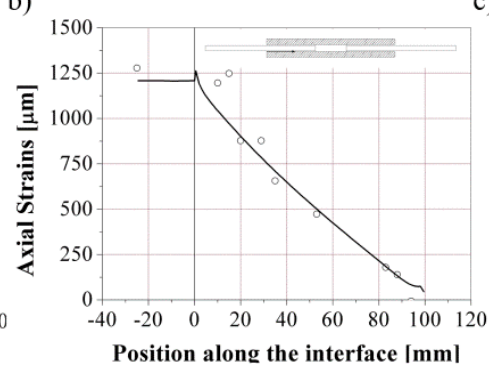

c)

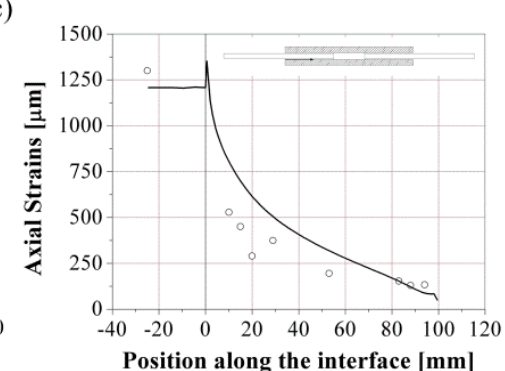

Figure 4. Measured (dots) and calculated (lines) axial strains at $5.0 \mathrm{kN}$ for Sikaflex (a) and at $20.0 \mathrm{kN}$ for Sikaforce (b) and Sikadur (c).

\subsection{Failure modes}

Figure 5 illustrates the typical failure modes for each type of adhesive. It can be seen that the $\mathrm{Si}$ kaforce and Sikadur specimens failed due to breakage of both glass adherends (Figs. 5b and 5c), indicating that those adhesives were able to efficiently transfer shear stresses from the glass to the GFRP without achieving their maximum stress transfer capacity. It is worth mentioning that specimen Sikaforce-1 presented a progressive damage in the bonded interfaces, noticeable by the consecutive noises audible during the tests (which may have been caused by the degradation of the adhesion for higher loads and/or effects of shear stress concentrations). The Sikaflex specimens also exhibited glass failure but only in one of the inner panes. In these specimens, failure was triggered by the debonding at one of the interfaces - a progressive slippage between adherends developed and it was clearly visible at the glass-adhesive interface prior to failure (Fig. 5a). Due to this slippage, load started to be transferred non-symmetrically, i.e. one of the glass panes progressively carried out an increasing fraction of the axial load. This is attested by the load vs. relative displacement behaviour and by the much lower failure load of these specimens (about half of the other series). 

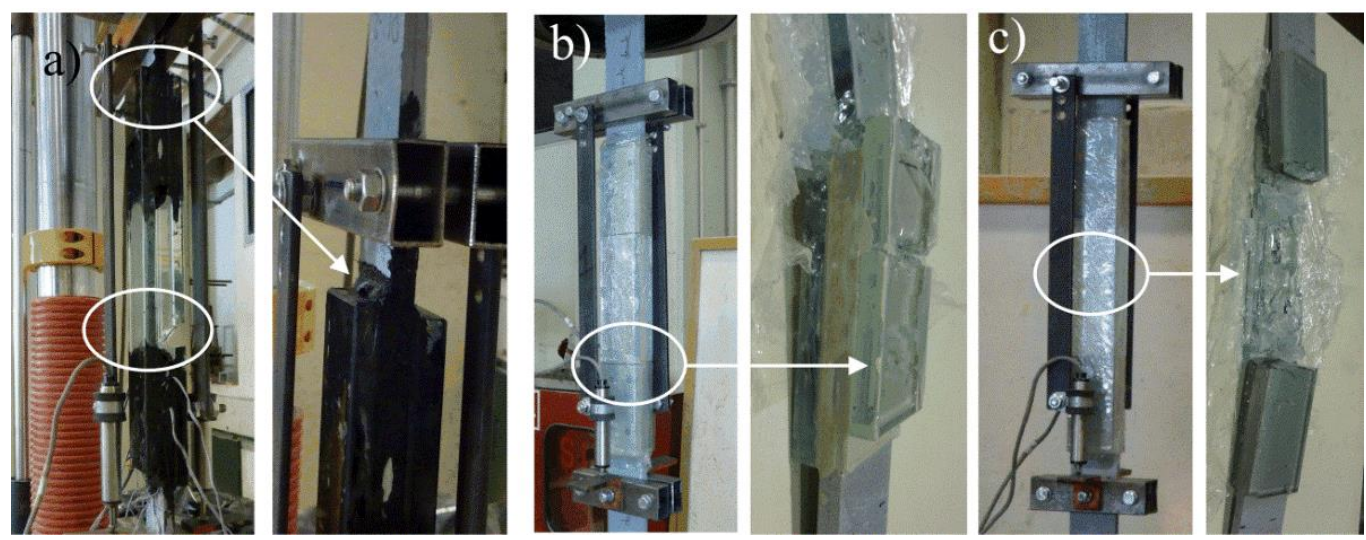

Figure 5. Failure modes of double lap joints made of (a) Sikaflex, (b) Sikaforce and (c) Sikadur adhesives.

\section{NUMERICAL INVESTIGATIONS}

\subsection{Initial considerations}

The numerical investigations comprised the development of non-linear finite element (FE) models of all joints tested. The main objective of the FE simulations was to retrieve the parameters that define the linear or non-linear constitutive relation of the bonded interfaces, namely the ones that define the shear behaviour of the interface elements for the three different adhesives. To that end the load $v s$. relative displacement experimental data were used to calibrate the parameters used as input in the numerical models.

\subsection{FE model description}

Only $1 / 4$ of the double lap joint specimens was modelled assuming that all specimens had a bisymmetrical behaviour. The double lap joints were modelled as a plane stress problem. The geometry, mesh, support conditions and load configuration used are shown in Figure 6.

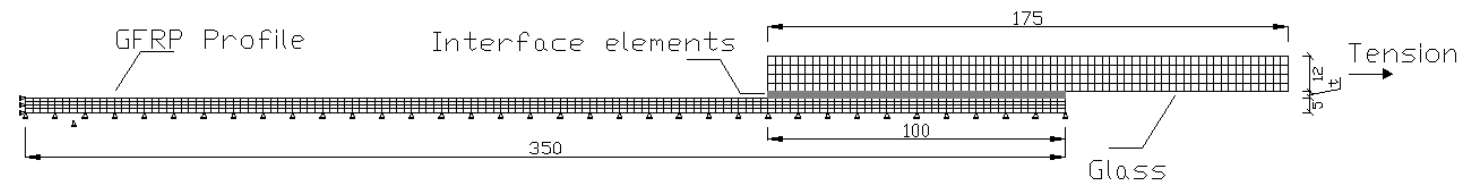

Figure 6. Mesh, support conditions and load configuration of the numerical model.

Both glass and GFRP materials were simulated using 8-node Serendipity plane stress elements with a $2 \times 2$ Gauss-Legendre integration scheme. The adhesive layer that connects the GFRP and glass adherends was simulated by a 6-node interface element with 3 points GaussLobatto integration rule, considering the two different thicknesses used. These elements allowed using two different models for the constitutive law: (i) a linear elastic law characterized by the normal and tangential stiffnesses $\left(\mathrm{K}_{\mathrm{n}}\right.$ and $\mathrm{K}_{\mathrm{t}}$, respectively), and (ii) a non-linear bond stress-slip relation defined by equation (1), where $\tau_{\mathrm{m}}$ and $\mathrm{s}_{\mathrm{m}}$ are respectively the bond strength and the corresponding slippage, being $\alpha$ and $\alpha^{\prime}$ the parameters that define the shape of the curves (SenaCruz 2004). The latter constitutive law also allows defining an initial linear branch before the non-linear bond stress-slip relationship.

$$
\tau(s)=\left\{\begin{array}{l}
\tau_{m}\left(\frac{s}{s_{m}}\right)^{\alpha} \\
\tau_{m}\left(\frac{s}{s_{m}}\right)^{\alpha \prime}
\end{array}\right.
$$




\subsection{Material input data}

Table 3 presents the material properties used to model each type of adhesively bonded specimens, in terms of normal $\left(\mathrm{K}_{\mathrm{n}}\right)$ and tangential $\left(\mathrm{K}_{\mathrm{t}}\right)$ stiffnesses when a linear elastic constitutive law was applied for the interface elements, or bond strength $\left(\tau_{\mathrm{m}}\right)$ and corresponding slippage $\left(\mathrm{s}_{\mathrm{m}}\right)$ for the non-linear bond stress-slip relation.

Glass was modelled as a linear elastic isotropic material with an elasticity modulus of $70 \mathrm{GPa}$ and a Poisson's ratio of 0.23 . The GFRP was simulated as a linear isotropic material (despite being orthotropic, for this simulation the transverse behaviour was not taken into account) with an elasticity modulus of $32.8 \mathrm{GPa}$ and a Poisson's ratio of 0.28 .

As already mentioned, the different adhesive layers were modelled using interface elements. For the Sikaflex and Sikaforce specimens a non-linear constitutive law was assumed. To simulate the Sikadur adhesive a linear constitutive law was adopted.

Table 3. Adhesive shear properties used on the FE simulations.

\begin{tabular}{lllllll}
\hline \multirow{2}{*}{ Adhesive } & $\mathrm{K}_{\mathrm{N}}$ & $\mathrm{K}_{\mathrm{t}}$ & $\mathrm{s}_{\mathrm{m}}$ & $\tau_{\mathrm{m}}$ & $\alpha$ & $\alpha^{\prime}$ \\
& {$[\mathrm{kN} / \mathrm{m} / \mathrm{m}]$} & {$[\mathrm{kN} / \mathrm{m} / \mathrm{m}]$} & {$[\mathrm{mm}]$} & {$[\mathrm{MPa}]$} & {$[-]$} & {$[-]$} \\
\hline Sikaflex265 & $*$ & $*$ & 4.200 & 1.70 & 0.90 & 3.00 \\
Sikaforce7710 L100 & $*$ & $*$ & 0.205 & 5.00 & 0.60 & $*$ \\
Sikadur31-cf & 13.1 & 650 & $*$ & $*$ & $*$ & $*$ \\
\hline
\end{tabular}

* Not applicable

\subsection{Calibration of the FE model - comparison of F vs. d curves}

The load vs. relative displacement curves obtained from the numerical models are plotted and compared with the experimental data in Figure 3. It can be seen that the numerical curves match the experimental ones. Therefore, it can be concluded that the parameters defining the interface elements adequately represented the bond behaviour granted by the tested adhesives, even in the Sikaflex and Sikaforce adhesives, for which the behaviour was non-linear. Two different failure criteria were set: (i) for the Sikaflex adhesive the simulation stopped when the maximum experimental displacement was attained, (ii) whereas for the Sikaforce and Sikadur adhesives, it stopped when the stress in the glass adherends reached the limits known to cause glass failure.

\subsection{Validation of the FE model-comparison of F vs. Ecurves}

Figure 4 shows the numerical results in terms of axial strains along the overlap length of the specimens and the respective comparison with the experimental results. As for the load vs. relative displacement curves, in spite of the relatively high scatter of experimental data, a general good agreement was obtained between measured strains and numerical results, providing further validation to the FE models and, in particular, of the parameters used to simulate the constitutive relations of the bonded interfaces. In other words, the interface elements were able to reproduce the different shear properties of the adhesives tested.

Figure 4 also shows that, as expected, the use of interface elements with higher stiffness leads to a steeper initial distribution of axial strains; in opposition, a lower stiffness is associated to a linear distribution of axial strains along the overlap length.

\section{CONCLUSIONS AND FUTURE DEVELOPMENTS}

This paper presented the results of experimental and numerical investigations on adhesively bonded double lap joints between annealed glass and GFRP adherends. The following main conclusions can be drawn:

- The tensile tests on double lap joints allowed assessing the behaviour of adhesively bonded joints between glass and GFRP profiles made of three different adhesives.

- The numerical models allowed determining the shear parameters that characterize the bonded interfaces comprising those three different adhesives. Furthermore, the parameterization made using the FE analyses was able to reproduce with a good level of accuracy the experimental response, both in terms of load vs. relative displacement and load vs. axial strain development along the GFRP-adhesive interfaces. 
- The use of interface elements in the numerical models to simulate the bonded interfaces, featuring two different constitutive laws (linear and non-linear), allowed reproducing the joint behaviour for a wide range of adhesive stiffnesses.

As future work the authors plan to develop single lap tests in order to further characterize the behaviour of the adhesives. For the stiffer adhesives, the tensile tests on double lap joints with the glass adherends in tension did not allow determining the peak point of the interface constitutive relation, since the ultimate failure of glass was achieved prior to the failure of the adhesive or the interface. Furthermore, the intrinsic redundancy of this test setup in general does not allow the full definition of the shear properties of the adhesive, since not all interfaces fail at the same time. Finally, the authors will also address the validity of this modelling procedure through the simulation of the flexural behaviour of glass-GFRP composite beams, recently tested by the authors (Correia et al. 2012, Valarinho et al. 2013).

\section{ACKNOWLEDGEMENTS}

The authors wish to acknowledge FCT, ICIST and ADI (project $n .{ }^{\circ} 3456 / 2009$ ) for funding the research and companies SIKA, Guardian, STEP and ALTO for having supplied the adhesives, the glass panes and the GFRP pultruded profiles used in the experiments, respectively. The first author also thanks FCT for scholarship n ${ }^{\circ}$ SFRH/BD/80234/2011.

\section{REFERENCES}

Correia JR, Valarinho L, Branco FA, Post-cracking strength and ductility of glass-GFRP composite beams, Composite Structures, Volume 93, Issue 9, August 2011, Pages 2299-2309.

European Committee for Standardization. EN 1288-1 Glass in building - Determination of the bending strength of glass - Part 1: Fundamentals of testing glass; Part 3: Test with specimen supported at two points (four point bending). CEN, Brussels, 2000.

ISO 527 Plastics - Determination of the tensile properties - Part 1: General principles. International Organization for Standardization, Genève, 1993.

ISO 527 Plastics - Determination of the tensile properties - Part 2: Test conditions for moulding and extrusion plastics. International Organization for Standardization, Genève, 1993.

ISO 527 Plastics - Determination of the tensile properties - Part 4: Test conditions for isotropic and orthotropic fibre-reinforced plastic composites. International Organization for Standardization, Genève, 1993.

Sena-Cruz JM, Strengthening of concrete structures with near-surface mounted CFRP laminate strips, $\mathrm{PhD}$ Thesis, Department of Civil Engineering, University of Minho, 2004, 198 pp. URI: http://hdl.handle.net/1822/11781.

Sena-Cruz JM, Barros JAO, Azevedo AFM, Ventura-Gouveia A, Numerical simulation of the nonlinear behavior of RC beams strengthened with NSM CFRP strips, Proceedings of the CMNE 2007 - Congress on Numerical Methods in Engineering and XXVIII CILAMCE - Iberian Latin American Congress on Computational Methods in Engineering, Abstract pp. 289, Paper $n^{\circ} 485$ published in CD FEUP, 20 pp., Porto, 13-15 June 2007.

Valarinho L, Correia JR, Sena-Cruz J, Branco FA, Numerical simulation of transparent glass-GFRP composite beams using smeared crack models. In: Bos, Louter, Nijsse, Veer (Eds.), Proceedings of challenging glass 3 Conference on architectural and structural applications of glass, Delft, 28-29 June 2012. Amsterdam: IOS press.

Valarinho L, Correia JR, Branco FA, Experimental study on the flexural behaviour of multi-span transparent glass-GFRP composite beams, Construction and Building Materials, Volume 49, December 2013, Pages 1041-1053.

Vandebroek M, Belis J, Louter C, Influence of the load history on the edge strength of glass with cut edge finishing. In: Bos, Louter, Nijsse, Veer (Eds.), Proceedings of challenging glass 3 Conference on architectural and structural applications of glass, Delft, 28-29 June 2012. Amsterdam: IOS press.

Veer F, Rodichev Y, The relation between fracture morphology and failure strength in annealed glass. In: Bos, Louter, Nijsse, Veer (Eds.), Proceedings of challenging glass 3 Conference on architectural and structural applications of glass, Delft, 28-29 June 2012. Amsterdam: IOS press. 